\title{
Intimate partner violence: a study in men and women from six European countries
}

\author{
Diogo Costa $\cdot$ Joaquim Soares $\cdot$ Jutta Lindert • \\ Eleni Hatzidimitriadou $\cdot$ Örjan Sundin $\cdot$ Olga Toth $\cdot$ \\ Elli Ioannidi-Kapolo $\cdot$ Henrique Barros
}

Received: 30 April 2014/Revised: 31 January 2015/Accepted: 3 February 2015/Published online: 20 February 2015

(C) Swiss School of Public Health 2015

\begin{abstract}
Objectives We aimed to assess intimate partner violence (IPV) among men and women from six cities in six European countries.

Methods Four IPV types were measured in a populationbased multicentre study of adults (18-64 years; $n=3,496)$. Sex- and city-differences in past year prevalence were examined considering victims, perpetrators or both and considering violent acts' severity and repetition. Results Male victimization of psychological aggression ranged from $48.8 \%$ (Porto) to $71.8 \%$ (Athens) and female victimization from $46.4 \%$ (Budapest) to $70.5 \%$ (Athens). Male and female victimization of sexual coercion ranged from 5.4 and $8.9 \%$, respectively, in Budapest to 27.1 and
\end{abstract}

Electronic supplementary material The online version of this article (doi:10.1007/s00038-015-0663-1) contains supplementary material, which is available to authorized users.

D. Costa $\cdot$ H. Barros

EPIUnit - Institute of Public Health, University of Porto, Porto, Portugal

J. Soares

Institution for Health Sciences, Mid Sweden University,

Sundsvall, Sweden

J. Lindert

University of Emden, Emden, Germany

J. Lindert

Brandeis University, Waltham, USA

E. Hatzidimitriadou

Faculty of Health and Social Care Sciences, Kingston

University, London, UK

E. Hatzidimitriadou

St George's, University of London, London, UK
$25.3 \%$ in Stuttgart. Male and female victims of physical assault ranged from 9.7 and $8.5 \%$, respectively, in Porto, to 31.2 and $23.1 \%$ in Athens. Male victims of injury were $2.7 \%$ in Östersund and $6.3 \%$ in London and female victims were $1.4 \%$ in Östersund and $8.5 \%$ in Stuttgart. IPV differed significantly across cities $(p<0.05)$. Men and women predominantly experienced IPV as both victims and perpetrators with few significant sex-differences within cities.

Conclusions Results support the need to consider men and women as both potential victims and perpetrators when approaching IPV.

Keywords Intimate partner violence $\cdot$ Europe $\cdot$ Population-based

Ö. Sundin

Department of Psychology, Mid Sweden University, Östersund, Sundsvall, Sweden

O. Toth

Institute of Sociology, Hungarian Academy of Sciences,

Budapest, Hungary

E. Ioannidi-Kapolo

National School of Public Health Athens, Athens, Greece

D. Costa $\cdot$ H. Barros $(\bowtie)$

Department of Clinical Epidemiology, Predictive Medicine and Public Health, University of Porto Medical School, Porto,

Portugal

e-mail: hbarros@med.up.pt 


\section{Introduction}

Intimate partner violence (IPV) is a violation of human rights and one of the most frequently experienced forms of violence (Garcia-Moreno et al. 2006). In 2002, the World Health Organization (WHO)-World Report on Violence and Health (Krug et al. 2002) described the prevalence of past year IPV against women as ranging from less than $3 \%$ in Australia, Canada and the United States (US) to more than $30 \%$ in Israel, Peru, West Bank and Gaza Strip. A 2013 WHO global systematic review showed that $35 \%$ of women ever experienced either physical and/or sexual IPV or non-partner sexual violence (WHO 2013). However, some countries in Europe such as Hungary, Portugal and Greece still lack such estimates.

Studies designed to measure the frequency and identify the determinants of IPV focus mostly on women as victims (Bonomi et al. 2009; Garcia-Moreno et al. 2006; Thompson et al. 2006; Yoshihama et al. 2007). However, a review of 91 studies showed that one in five men was a victim of IPV (Desmarais et al. 2012a) and poor health outcomes have been associated with male victimization (Reid et al. 2008).

IPV against women tends to be a repetitive act though with varied frequency. Over $15 \%$ of ever-injured women in Brazil, Peru or Thailand but only $1 \%$ of Ethiopian women reported that it happened more than five times in their life (Ellsberg et al. 2008). Descriptions, interpretations and international comparisons of IPV may lose insight without information on repetition of acts. The chronicity dimension might additionally elucidate any sexdifference of IPV (Johnson 1995) since one of the criticisms of prevalence surveys is that simple "counts" of acts might translate into false sex-symmetric rates if not accounting for systematic patterns or repetition of acts (Kimmel 2002).

Little is known on reciprocal violence in the general population (Caetano et al. 2005), defined as simultaneous involvement in perpetration and victimization. A sample of 848 blue-collar American couples showed a $14.2 \%$ prevalence of reciprocal, $6.1 \%$ male-to-female only and $9.3 \%$ female-to-male only violence (Cunradi et al. 2011). In young American couples reciprocal violence was as common as non-reciprocal, but more likely to result in injury (Whitaker et al. 2007). In an analysis of 1,046 couples representing married and cohabiting couples from 48 states in the USA, approximately $8 \%$ reported reciprocal violence, close to $4 \%$ reported that there was perpetration of violence by the male partner only and approximately $2 \%$ reported the perpetration of violence by the female partner only (Caetano et al. 2008). No information on the magnitude of reciprocal violence is available for the adult European general population and cross-cultural comparisons are limited to physical and sexual IPV against women. Psychological abuse has been less studied and may further help explaining other components of male and female IPV experiences.

The observed geographical differences in IPV against women can reflect real variability or just different study designs, making figures not directly comparable. This paper presents results of the DOVE project-domestic violence against men/women in Europe, designed to compare IPV victimization and perpetration in men and women from the general population using a multi-country sample and the same IPV definitions.

\section{Methods}

DOVE was a cross-sectional multicentre study involving non-institutionalized adults (18-64 years) from eight European cities: Ghent-Belgium, Stuttgart-Germany, AthensGreece, Budapest-Hungary, Porto-Portugal, GranadaSpain, Östersund-Sweden and London-United Kingdom (UK). Sites were selected based on previous collaboration (Lindert et al. 2012; Priebe et al. 2013), and to represent geographical and cultural diversity across Europe.

\section{Study design and participants}

Detailed description of DOVE's design and participants characteristics' is available elsewhere (Costa et al. 2013). The sample size was established on the basis of required levels of statistical power to estimate and compare the prevalence of IPV across sites. Assuming an IPV prevalence of $15 \%$ (Breiding et al. 2008) and $3.0 \%$ of relative precision, samples size was calculated as 544 (272 women) per centre representing a proportionally stratified age- and sex-distribution of the resident population (2008 national data). Four sampling strategies were used: registry-based in Stuttgart and Östersund, registry-based and random-digit-dialling in Porto, registry-based and viapublic approach in London and random-route in Athens and Budapest. Registries were municipal in Stuttgart, electoral in Porto and London, and the state person-address in Östersund. Invitation letters with a concise project description were sent to participants selected based on registries. The study was presented by interviewers as part of the invitation procedure to participants contacted through telephone or at their houses.

For the present study 3,496 (women $=2,026)$ participants from six centres were considered (Supplementary Table 1). Data from Ghent $(n=245)$ and Granada $(n=138)$ were excluded since the target sample size was not achieved. 
Socio-demographic characteristics included sex, age, education (categorized in secondary level or less and university degree), marital status (single, cohabiting, married or separated/divorced) and migrant background (participants indicating another place of birth than the country they lived in or another nationality). These were collected by face-to-face interview in Athens, Budapest, Porto and London. In Östersund, as per ethics demand, questionnaires were mailed and returned using a pre-paid envelope. In Stuttgart, a number of face-to-face interviews were conducted but most questionnaires were mailed $(74.5 \%)$. Also in Porto (14.0\%) and London (3.5\%), a small proportion of participants opted for participation by post. In all sites, the IPV section was self-administered. Data collection took 9 months and was completed in May 2011.

\section{Outcome measures}

The same standardized and validated questionnaire was selfadministered by participants in all centres to assess IPV, ensuring that the definition of IPV types assessed was the same. Past year prevalence of IPV against men and against women was assessed using validated versions of the Revised Conflict Tactics Scales (CTS2) (Straus et al. 2003), originally developed in English, available in Portuguese, German and Swedish (Straus 2004; Straus and Mickey 2012). Translations to Greek and Hungarian followed a standard protocol: forward translation, expert panel revision, back-translation, new expert panel revision and piloting. The CTS2's act-specific type of questioning was used in cross-cultural research on IPV against women, namely in the WHO multi-country study (GarciaMoreno et al. 2006) or the Demographic Health Surveys (DHS) (Palermo et al. 2013) and in the study of elder abuse (Lindert et al. 2013). The CTS2 allows to measure psychological aggression (8 items), physical assault (12 items), sexual coercion ( 7 items) and injury (6 items). For each act, the participant answers two questions: the frequency of the act by a current or former partner (victimization) and the frequency by the participant (perpetration), i.e. each participant responded from both perspectives: as a victim and as a perpetrator.

Participants were asked "How often did this happen in the past year?", and eight frequency options given: once in the past year, twice, 3-5 times, 6-10 times, 11-20 times, more than 20 times, not in the past year but ever happened, and never happened.

The questions covered acts of "minor" or "severe" violence according to risk of injury that would require medical attention (Straus et al. 2003). Even though "moderate" and "severe" may be considered more appropriate terms, we followed the original scales' author terminology.

The frequency of abuse was categorized as once, $2-5$ and more than 5 times, and was considered a measure of chronicity instead of the mean number of acts to overcome the skewed sample distribution (Straus et al. 1996). Participants were characterized as victims or perpetrators of "minor" or "severe" violence according the severity of the reported act.

Ethical considerations

The WHO ethical and safety guidelines (Ellsberg and Heise 2002) were taken account in the fieldwork design and the study protocol was approved by local Research Ethic Committees, ensuring that the principles of anonymity and informed consent were upheld.

Interviewers received instructions for conducting interviews in the presence of the participant alone. If privacy was not ensured, the interviewer would kindly apologize and stop the questioning. When there was face-to-face contact, participants were given an envelope where to put the self-administered violence-module of the questionnaire, that was sealed and returned to the interviewer. The training of interviewers followed a standardized protocol, previously created by the research team. It included presentation of the project aims, role-playing involving scenarios related to introducing the interview, dealing with difficult participants and sensitive situations during the interview, research ethics and safety of participants and researchers during field work including handling of reported/witnessed IPV incidents, and a crisis-intervention protocol. The voluntary character of participation was emphasized and although written informed consent was asked to all face-to-face interviewed participants, no link between signed consents and questionnaires existed.

\section{Data analysis}

Sex-specific, age-standardized (European standard population) past year period-prevalence (and $95 \%$ confidence intervals) of victimization and perpetration was calculated. For each violence type and sex, the frequency of unidirectional and bidirectional/reciprocal [being victims and perpetrators of the same type of violence (Whitaker et al. 2007)] was computed. Chi-square and Fisher exact tests were used to compare prevalence by sex, city and violence type. SPSS v20 was used for analysis.

\section{Results}

Victimization

Psychological aggression

The prevalence of women victims of psychological aggression ranged from $46.4 \%(41.3-51.6 \%)$ in Budapest to $70.5 \%(65.1-75.8 \%)$ in Athens (Fig. 1). Porto (48.8, 
Fig. 1 Past year agestandardized prevalence of acts of victimization (any severity), (conducted in six European cities during 2010-2011). $* p<0.05$ for sex comparison of past year estimates within country; all other site comparisons for past year estimates were statistically significant, $p<0.05$; error bars illustrate $95 \%$ confidence intervals

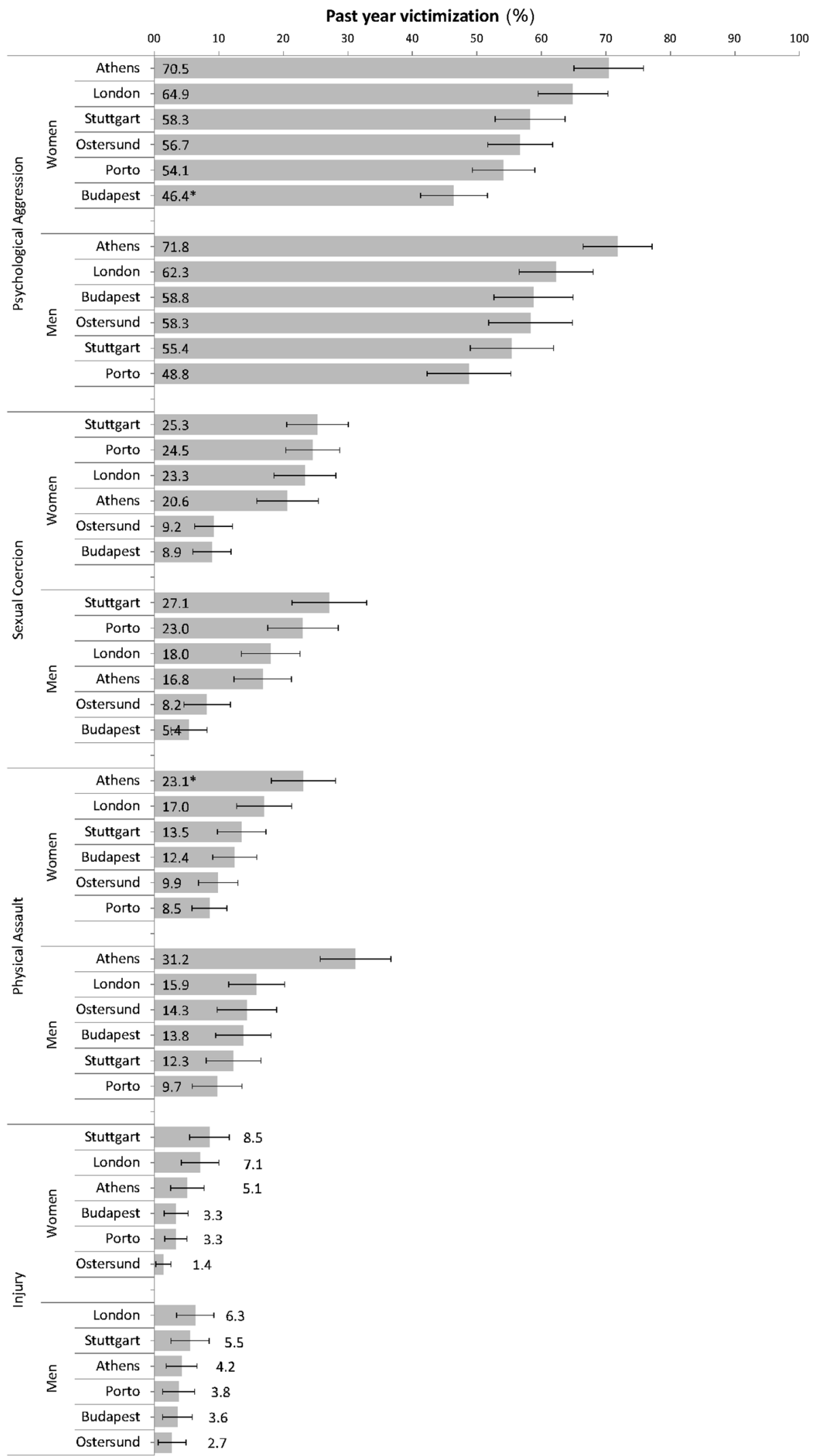


42.3-55.3\%) presented the lowest and Athens (71.8, $66.5-77.2 \%)$ the highest prevalence of male victims. Severe acts were reported by $37.4 \%(31.6-43.2 \%)$ of men and $30.0 \%(24.6-35.4 \%)$ of women in Athens and by $9.7 \%(5.8-13.6 \%)$ and $8.0 \%(5.2-10.8 \%)$, respectively, in Östersund (Fig. 2).

The prevalence of psychological aggression of both sexes was similar in every city except Budapest, where men reported more often being victims (58.8 vs. $46.4 \%$, $p=0.04$ ), either of minor (31.6 vs. $26.3 \%$ ) or severe acts (27.0 vs. $19.9 \%, p=0.01$ ).

\section{Sexual coercion}

Sexual coercion was reported by $9.2 \%(6.2-12.1 \%)$ of women in Östersund and $8.9 \%(6.0-11.9 \%)$ in Budapest, being over $20 \%$ in the remaining cities (Fig. 1). In men, estimates ranged from $5.4 \%(2.6-8.2 \%)$ in Budapest to $27.1 \%(21.3-32.9 \%)$ in Stuttgart. In women, the frequency of severe acts was lower in Östersund (1.7, 0.4-3.0 \%) and higher in London (9.2, 5.9-12.5\%), with no male cases in Östersund and $5.5 \%(2.8-8.2 \%)$ in Athens men (Fig. 2).

\section{Physical assault}

Porto presented the lowest rates of physical assault (women: 8.5, 5.8-11.2\%; men: 9.7, 5.9-13.6\%) and Athens the highest (women: 23.1, 18.1-28.1\%; men: 31.2, 25.7-36.7\%, $p=0.040$ ) (Fig. 1). Severe acts in women ranged from $3.0 \%(1.1-4.9 \%)$ in Stuttgart to $14.7 \%(10.5-18.9 \%)$ in Athens and in men from $3.5 \%(1.1-5.9 \%)$ in Stuttgart to $19.6 \%$ (14.9-24.3\%) in Athens (Fig. 2).

\section{Injury}

Women from Östersund reported the lowest prevalence of injury $(1.4,0.2-2.6 \%)$ while the highest was in Stuttgart $(8.5,5.5-11.6 \%)$ (Fig. 1). In men, estimates ranged from $2.7 \%(0.6-4.9 \%)$ in Östersund to $6.3 \%(3.4-9.2 \%)$ in London. Severe acts in women ranged from $0.3 \%$ $(0.0-0.9 \%)$ in Östersund to $3.6 \%(1.5-5.7 \%)$ in London (Fig. 2). No severe cases were observed in Östersund while in London the prevalence was $3.7 \%$ (1.5-5.9\%).

\section{Perpetration}

\section{Psychological aggression}

Women perpetration ranged from $48.9 \%(43.7-54.1 \%)$ in Budapest to $74.7 \%(69.6-79.9 \%)$ in Athens while in men it ranged from $51.5 \%(45.0-58.0 \%)$ in Porto to $71.4 \%$
(66.9-76.7\%) in Athens (Fig. 3). Sex-differences were found in Stuttgart (women: $66.6 \%$; men: $55.8 \%$, $p=0.019$ ) and Budapest (women: $48.9 \%$; men: $58.1 \%$, $p=0.030)$. Severe acts, in women and men, were less frequent in Östersund $(6.0,3.6-8.4 \%$, and 6.3, 3.1-9.5 \%, respectively) and more frequent in Athens (30.0, 24.6-35.4\% and 39.1, 33.3-44.9\%) (Fig. 4).

Significant sex-differences in severity of acts were noticed in Athens $(p=0.009)$ and Stuttgart $(p=0.039)$.

\section{Sexual coercion}

Budapest (women: 3.6, 1.7-5.6\%, men: 10.6, 6.8-14.4\%, $p=0.002$ ) and Stuttgart (women: $23.5,18.8-28.1 \%$, men: $30.6,24.6-36.6 \%$ ) presented the extreme rates and significant sex-differences were observed in all cities, except Stuttgart ( $p$-values $<0.001$ in Porto and Östersund, $p=0.001$ in Athens and $p=0.047$ in London, Fig. 3). Severe acts in women ranged from $0.3 \%(0.0-0.9 \%)$ in Östersund to $2.8 \%(0.9-4.7 \%)$ in London (Fig. 4). No male cases were recorded in Stuttgart and Östersund, the prevalence in London being $5.0 \%$ (2.4-7.6 \%).

Significant sex-differences in severity of acts were observed in Porto $(p=0.001)$, Athens $(p=0.004)$, Östersund ( $p=0.001)$ and Budapest $(p=0.002)$.

\section{Physical assault}

Women perpetration ranged from $10.0 \%(7.1-13.0 \%)$ in Porto to $21.6 \%(16.8-26.5 \%)$ in Athens, and by men from $9.6 \%(5.8-13.5 \%)$ in Porto to $33.0 \%(27.4-38.6 \%)$ in Athens (Fig. 3). Severe acts perpetrated by women ranged from $1.1 \%(0.0-2.2 \%)$ in Östersund to $12.1 \%$ (8.3-15.9 \%) in Athens, and by men from $1.0 \%(0.0-2.3 \%)$ in Stuttgart to $21.8 \%(16.9-26.7 \%$ ) in Athens (Fig. 4).

Significant sex-differences were found in Athens $(p=0.004)$, with more male perpetration.

\section{Injury}

Women that perpetrated injuries ranged from $2.8 \%$ $(1.1-4.5 \%)$ in Östersund to $9.4 \%(5.9-12.8 \%)$ in Athens, and from $1.7 \%(0.0-3.4 \%)$ in Östersund to $9.0 \%$ (5.3-12.7\%) in Stuttgart regarding men, with significant sex-differences in Athens (women: $9.4 \%$; men: $3.9 \%$, $p=0.019$ ) (Fig. 3). Considering women, severe acts ranged from $0.3 \%(0.0-0.9 \%)$ in Östersund to $5.0 \%$ (2.5-7.5\%) in London (Fig. 4). No male cases were recorded in Östersund, but the prevalence was $4.2 \%$ (1.8-6.6 \%) in London.

In Athens, women significantly more frequently perpetrated minor and severe acts $(p=0.021)$. 
Fig. 2 Past year agestandardized prevalence of acts of victimization (minor and severe acts), (conducted in six European cities 2010-2011). Asterisk difference between men and women is statistically significant $(p<0.05)$; severe counts participants who suffered at least one act of severe violence in the past year; minor only counts participants who declared being victims of only minor acts of violence in the past year; all site comparisons for past year estimates were statistically significant, $p<0.05$; error bars illustrate $95 \%$ confidence intervals for severe acts
Past year victimization (\%)

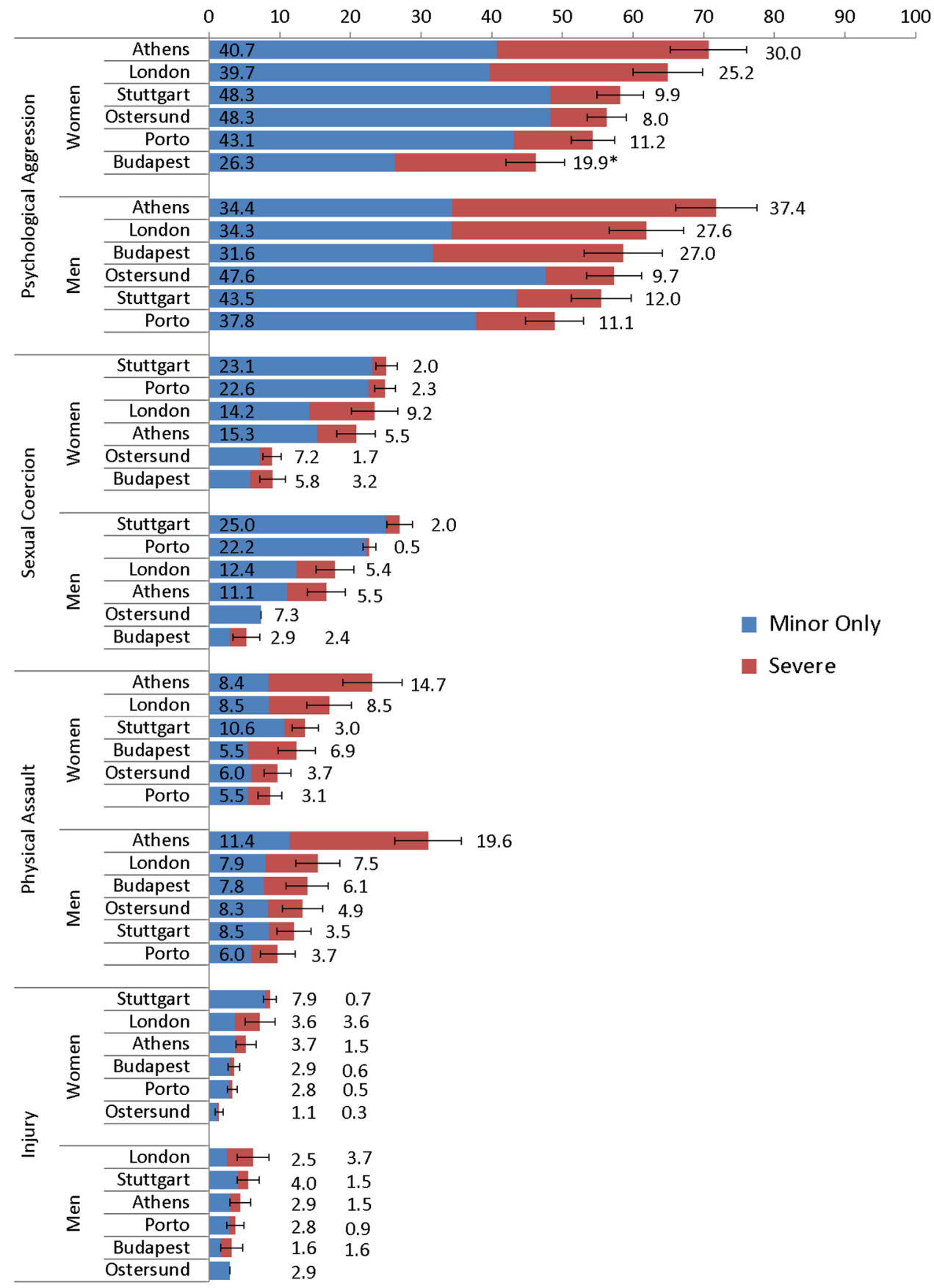

\section{Directionality}

Bidirectional or reciprocal (being involved as both victims and perpetrators) was the predominant pattern of violence (Supplementary Table 4). Significant sex-differences in the overall sample were observed for psychological aggression (only-victims, only-perpetrators and bidirectional IPV, respectively, were, men:4.1, 3.5 and $54.5 \%$ vs. women: $2.0,5.0,54.4 \%, p=0.001)$ and for sexual coercion (men: $3.0,7.5$ and $12.5 \%$ vs. women: 7.7, 1.6 and $9.7 \%, p<0.001)$.

\section{Chronicity of victimization}

Violence was experienced repeatedly (Supplementary Tables 2, 3). Considering the number of acts of severe 
Fig. 3 Past year agestandardized prevalence of acts of perpetration (any severity), (conducted in six European cities during 2010-2011). $* p<0.05$ for sex comparison of past year estimates within country; all other site comparisons for past year estimates were statistically significant, $p<0.05$; error bars illustrate $95 \%$ confidence intervals
Past year perpetration (\%)

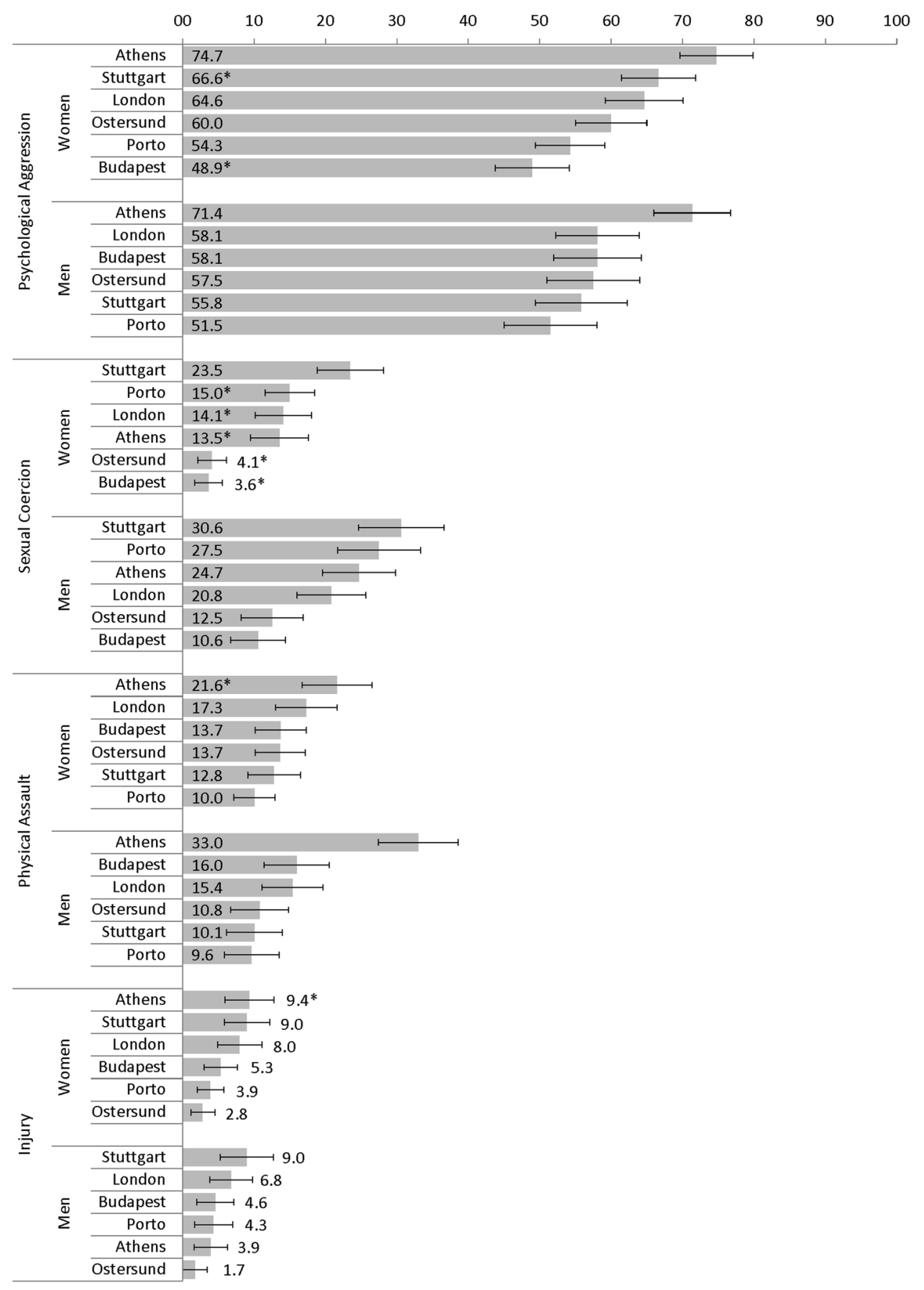

psychological aggression victimization, significant sexdifferences were found in Östersund $(3.8 \%$ of women sustained at least one severe act $2-5$ times and $4.1 \%$ of men sustained only once) and in London (12.4\% of women were victims of a severe act more than 5 times while $13.2 \%$ of men $2-5$ times).

For minor physical assault, significant sex-differences were found in Athens $(10.1 \%$ of women were victims of one act more than 5 times and $11.4 \%$ of men only once).
Also in Budapest men and women differed $(3.9 \%$ and $3.1 \%$ of women being victims $2-5$ times and more than 5 times, respectively, while men $4.8 \%$ once and $5.2 \%, 2-5$ times). Sex-differences were also observed for severe physical assault in Stuttgart (2.2\% of women were victims once and $2.2 \%$ of men 2-5 times). Significant sex-difference was found for minor injury in Athens $(2.5 \%$ of women reported at least one act more than 5 times and $1.8 \%$ of men reported only once). 
Fig. 4 Past year agestandardized prevalence of acts of perpetration (minor and severe acts), (conducted in six European cities during 2010-2011). Asterisk difference between men and women is statistically significant $(p<0.05)$; severe counts participants who suffered at least one act of severe violence in the past year; minor only counts participants who declared being victims of only minor acts of violence in the past year; all site comparisons for past year estimates were statistically significant, $p<0.05$; error bars illustrate $95 \%$ confidence intervals for severe acts
Past year perpetration (\%)

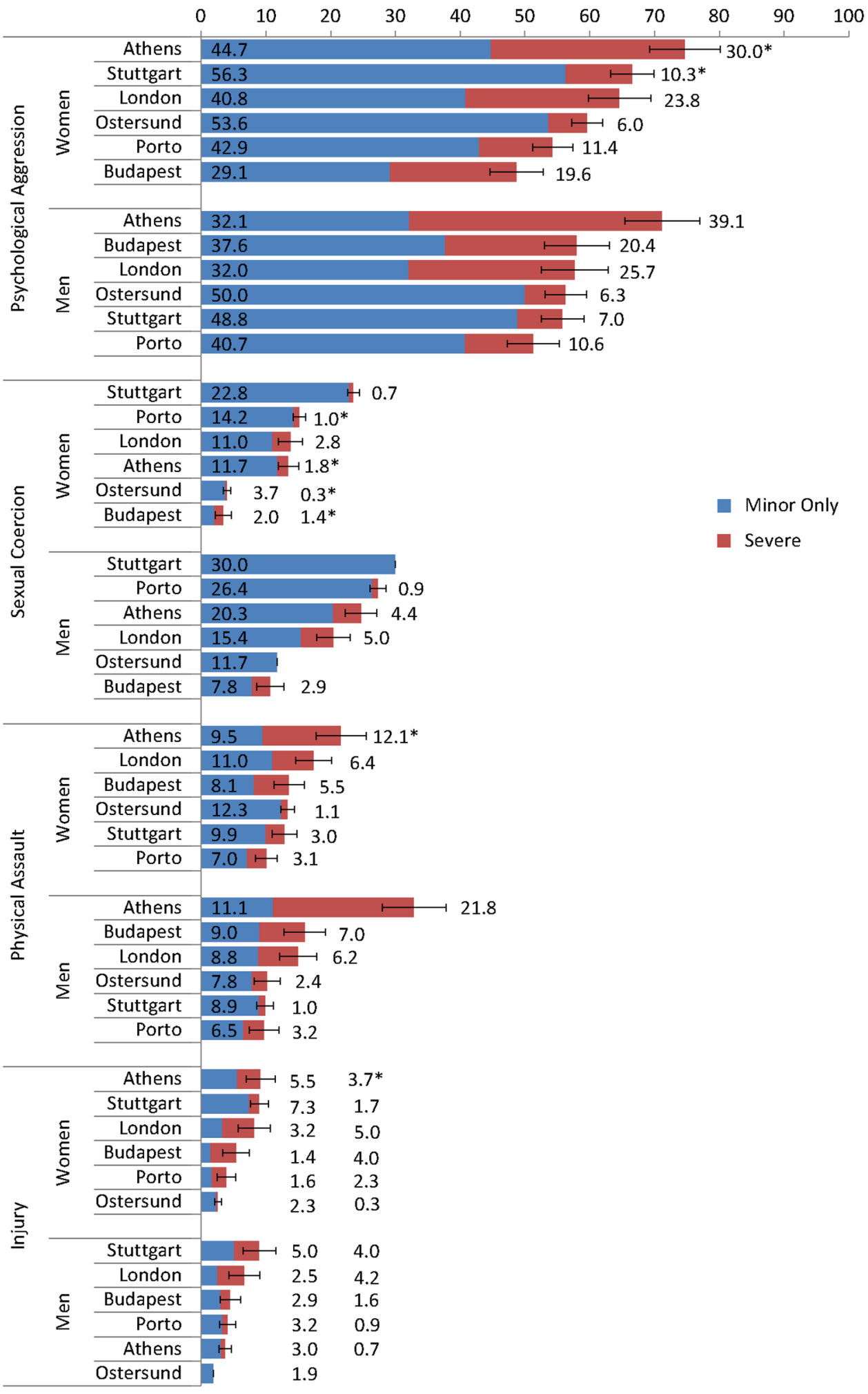




\section{Chronicity of perpetration}

With few exceptions, chronicity of perpetration was similar within each city according to sex (Supplementary Table 3): in Budapest, more than 5 minor psychological aggression acts were declared by $18.3 \%$ of women and $2-5$ times by $27.8 \%$ of men. In Porto, 20.3 and $16.4 \%$ of women reported minor acts of psychological aggression 2-5 times and more than 5 times, respectively, while $28.6 \%$ of men reported them 2-5 times. Also in Porto, more than 5 acts of minor sexual coercion were declared by $15.0 \%$ of men and $8.1 \%$ of women.

In Athens, men and women differed by minor physical assault (14.7\% of men reported once and $5.8 \%$ of women) and severe injury ( 7 women reported to perpetrate one act once, while no men did).

\section{Discussion}

This study suggests that IPV is a frequent plight among men and women living in these European urban centres, and that its prevalence and relative proportion of types present large geographical variation. However, within each city, men and women presented equivalent prevalence of victimization and perpetration except for sexual coercion, more often perpetrated by men. Men and women experienced repeated episodes of IPV, be it "minor" or "severe", and reciprocal IPV was preponderant in all sites.

\section{Intimate partner violence prevalence}

Our prevalence estimates for physical IPV are similar to those reported in the US for the past 10 years (Desmarais et al. 2012a, b). However, we found higher estimates compared to those documented for the settings with higher incomes present in the WHO multi-country study (Garcia-Moreno et al. 2006), which were Japan (3.1\% for physical IPV against women and $1.3 \%$ for sexual IPV) and Serbia and Montenegro (3.2\% physical IPV and $1.1 \%$ sexual IPV). Our estimates were also higher when compared to those observed in the International Violence Against Women Surveys (IVAWS) European sites (Johnson et al. 2008), for which past year physical IPV against women ranged from $1 \%$ in Denmark and Switzerland to $8 \%$ in Czech Republic.

European nation-wide studies of IPV in both genders have been conducted in the UK, Denmark and Sweden, although differences in study design and IPV definitions hinder comparisons. Nevertheless, the British Crime Survey (Khalifeh et al. 2013) points to past year estimates of physical IPV against men of $1.3 \%$ and of $2.0 \%$ against women, whereas in Denmark (Sorensen et al. 2012) these were $6.4 \%$ in men and $5.0 \%$ in women, lower than our results. Two studies conducted in Sweden (through post), one using the WHO tool (Nybergh et al. 2013) and another using the CTS2 (Lovestad and Krantz 2012) showed that past year physical IPV against men was 7.6 and $11 \%$, respectively, and against women it was 8.1 and $8 \%$, while sexual IPV male victims were 2.3 and $0.6 \%$ and female victims were 3.0 and $3.2 \%$. Also a study conducted among women living in Germany (Stockl et al. 2011) showed that $15 \%$ ever experienced physical violence and $17 \%$ experienced physical or sexual violence.

We considered acts of physical and sexual IPV, regardless of severity, which might partially explain our higher estimates. When we considered only "severe" acts of physical assault victimization, our results lay in the same range as those cited (Fig. 2), except in Athens, showing a significantly higher prevalence.

No further recent comparable data were available for the other countries concerned and psychological IPV against men and women has been much less studied, mainly because of lack of agreement on standard measures and definitions (WHO 2013).

Previous cross-cultural research on violence against women has suggested that societal factors such as attitudes towards IPV (cultural acceptance of violence as normative behaviour) (Uthman et al. 2010) and country-level socioeconomic features (Uthman et al. 2009), may explain country differences observed in the status of women and men in society and thus relate to the cross-country variation in prevalence. Such factors might also explain the variation observed in our study, although the city-differences seemed specific to the type of violence: for example, physical assault was more reported by participants in Athens and less so in Porto, but this difference was reversed when reporting sexual coercion. This may be an interesting difference considering that Portugal and Greece present worse socioeconomic indicators and the lowest level of gender equality (EIGE 2013) compared to the other sites in the study. Other cultural specificities should be explored for each violence type in these industrialized settings.

\section{Differences between sexes}

Within each city, the frequency of victimization and perpetration of psychological aggression, physical assault and injury was similar between men and women. A meta-analysis of 82 studies assessing aggression suggested that women were more likely than men to practice physical aggression acts and to do it more frequently while men were more likely to inflict injury (Archer 2000). Our findings appear to confirm this, favouring theories of social roles that explain similarities in male and female IPV as a result of the evolving gender equality of western societies (Archer 2009). 
Additionally, sexual coercion perpetration was different between men and women. In the Swedish general population more past year sexual coercion victimization was also found in women $[3.2$ vs. $0.6 \%$ with the use of the CTS2 (Lovestad and Krantz 2012) and 3.0 vs. $2.3 \%$ with the WHO tool (Nybergh et al. 2013)] while perpetration was declared by $5.2 \%$ of men and $0.8 \%$ of women. As with other self-reported sensitive and private issues, gender and country-specific stigma about IPV perpetration may impact on self-disclosure, although if this was the case, we would expect larger within-country differences than those noted. Likewise, using the CTS2 individual data (compared to couple data) to assess IPV may lead to underreporting, both in men and women, but even more in men (Archer 1999; Chan 2011). However, such information pertains mainly to physical assault and if male reporting of sexual coercion was affected, the observed sex-difference would be wider.

Recent studies have reported that sex-differences might be only found in lifetime victimization and perpetration estimates when compared to past year estimates, reflecting women's more severe experiences (Lovestad and Krantz 2012; Nybergh et al. 2013). However, an analysis of lifetime prevalence for the four types of IPV assessed (Supplementary Tables 5, 6) revealed the same crosscountry differences as noted for past year estimates and sex-differences within each site also followed the same pattern found for past year estimates.

\section{Chronicity}

The chronicity of abusive acts helps to explain sex-differences according to the type of IPV. For instance, the construct of intimate terrorism describes a type of abuse repeatedly perpetrated by men against women, whereas common couple violence, suggested as typical of the general population, tends to be less severe and less frequent (Johnson and Ferraro 2000). As presented in Supplementary Tables 2 and 3, the frequencies of abusive acts of victimization or perpetration were similar in men and women for all IPV types, supporting a gender equivalence in IPV that favours social theories associating women's empowerment to the traditional profile assumed with their partners (Hines 2007). However, our chronicity analysis pertains only to the abuse experienced during the previous year, not allowing to clearly test the presence of intimate terrorism, which might be underestimated in populationbased studies with this type of approach (Johnson et al. 2014).

\section{Bidirectional violence}

Previous studies suggested that IPV perpetration by both partners within a relationship is fairly common, but this was criticized under the assumption that differences would be revealed if the severity and repetition of acts was assessed (Whitaker et al. 2007). In our study, bidirectionality (being involved simultaneously as a victim and as a perpetrator) was accompanied by similar severity and chronicity confirming previous studies (Riggs et al. 2000). The focus on the protection of women victims and restriction of men-perpetrators has to evolve towards a general victim protection and restriction of perpetrators, continuing actions to prevent violence against women but raising awareness to prevent IPV on men.

\section{Study limitations}

We cannot rule out bias in prevalence estimates due to differences in sampling and data collection. We did not collect information on refusals or response rates. However, a comparison of participant's characteristics sampled from different sources, within the same city (performed in Porto and London) (Costa et al. 2013), suggests that the sampling method may not have biased participants' characteristics mix.

The CTS2 was self-completed without intervention of interviewers. Nevertheless, mailed questionnaires may have resulted in a lower disclosure, particularly if participants filled the questionnaire without privacy (namely with the presence of their partner) as opposed to the private setting ensured in sites where a trained interviewer introduced the questionnaire. This might explain the lower IPV rates observed in Östersund. However, in Stuttgart, IPV rates were amongst the highest, therefore, if any underestimation existed due to low disclosure induced by the post method, we would expect even higher prevalence estimates.

Regarding the use of telephone, bias might arise if landlines do not cover specific groups (ex: lower socioeconomic position). Only in Porto was this method used for recruiting and an older than expected population assessed. Our samples' age and educational profiles were compared with the general population characteristics' as provided by the respective National Statistics Institutes (five-age groups, by sex) and Eurostat country estimates (education) and a slight over-recruitment of older people in Porto, Östersund and Budapest and of more educated people in all sites was observed (Costa et al. 2013). Additional standardization for education did not affect the estimates (results not shown), and if residual confounding remained violence prevalence would be underestimated (Bangdiwala et al. 2004).

The CTS2 has been criticized for not measuring contextrelated features of IPV and only counting acts of violence. Contextual and meaning variables of interest should be the focus of further research efforts, assessed with separate valid instruments along with the CTS2 (Straus 2012). 


\section{Conclusions}

This is the first study reporting comparable data on four IPV types in six cities of six countries, contrasting adult men and women from the general population and detailing the perspectives of victims, perpetrators and of those declaring both. Even though different sampling techniques were used, all aimed to provide probabilistic samples of each city resident's and the remaining procedures that were taken account during the study design (sample size calculation allowing appropriate statistical power to determine IPV prevalence and cross-city comparisons, the use of the same training and standardized questionnaire in all centres) ensure the validity of these results.

The high prevalence rates and the variation observed in these European cities for psychological aggression, physical assault, sexual coercion and injury as types of IPV, emphasizes the significance of preventive interventions, given the well-known consequences to health associated with IPV. These results also emphasize the need to consider city-level characteristics that influence men's and women's reports of IPV. Similar prevalence estimates between men and women within the same city and the bidirectional or reciprocal pattern (being both a victim and perpetrator) observed in the experiences of psychological aggression, physical assault and injury must be considered in the design and the evaluation of preventive interventions.

Acknowledgments The authors would like to thank all men and women who generously participated in the DOVE project in the different cities across Europe. This work was supported by the Executive Agency for Health and Consumers-European Commission [contract number: 20081310] and the Fundação para a Ciência e Tecnologia [SFRH/BD/66388/2009 and PTDC/SAU-SAP/122904/ 2010].

Conflicts of interest None declared.

\section{References}

Archer J (1999) Assessment of the reliability of the conflict tactics scales: a meta-analytic review. J Interpers Violence 14:1263-1289. doi:10.1177/088626099014012003

Archer J (2000) Sex differences in aggression between heterosexual partners: a meta-analytic review. Psychol Bull 126:651-680. doi:10.1037/0033-2909.126.5.651

Archer J (2009) Does sexual selection explain human sex differences in aggression? Behav Brain Sci 32:249-311. doi:10.1017/ S0140525X09990951

Bangdiwala SI, Ramiro L, Sadowski LS, Bordin IA, Hunter W, Shankar V (2004) Intimate partner violence and the role of socioeconomic indicators in WorldSAFE communities in Chile, Egypt, India and the Philippines. Inj Control Saf Promot 11:101-109. doi:10.1080/15660970412331292324
Bonomi AE, Anderson ML, Cannon EA, Slesnick N, Rodriguez MA (2009) Intimate partner violence in Latina and non-Latina women. Am J Prev Med 36:43-48. doi:10.1016/j.amepre.2008. 09.027

Breiding MJ, Black MC, Ryan GW (2008) Prevalence and risk factors of intimate partner violence in eighteen U.S. states/territories, 2005. Am J Prev Med 34:112-118. doi:10.1016/j.amepre.2007. 10.001

Caetano R, Ramisetty-Mikler S, Field CA (2005) Unidirectional and bidirectional intimate partner violence among white, black, and hispanic couples in the United States. Violence Vict 20:393-406. doi:10.1891/0886-6708.20.4.393

Caetano R, Vaeth PAC, Ramisetty-Mikler S (2008) Intimate partner violence victim and perpetrator characteristics among couples in the United States. J Fam Violence 23:507-518. doi:10.1007/ s10896-008-9178-3

Chan KL (2011) Gender differences in self-reports of intimate partner violence: a review. Aggress Violent Behav 16:167-175. doi: 10.1016/j.avb.2011.02.008

Costa D, Soares JJ, Lindert J, Hatzidimitriadou E, Karlsso A, Sundin Ö, Toth O, Ioannidi-Kapolou E, Degomme O, Cervilla J, Barros $\mathrm{H}$ (2013) Intimate partner violence in Europe: design and methods of a multinational study. Gac Sanit 27:558-561. doi:10.1016/j.gaceta.2013.03.001

Cunradi CB, Ames GM, Duke M (2011) The relationship of alcohol problems to the risk for unidirectional and bidirectional intimate partner violence among a sample of blue-collar couples. Violence Vict 26:147-158. doi:10.1891/0886-6708.26.2.147

Desmarais S, Reeves K, Nicholls T, Telford R, Fiebert M (2012) Prevalence of physical violence in intimate relationships: part 1 . Rates of male and female victimization. Partner Abuse 3:1-6. doi:10.1891/1946-6560.3.2.140

EIGE (2013) Gender equality index-main findings. European Institute for Gender Equality, Italy

Ellsberg M, Heise L (2002) Bearing witness: ethics in domestic violence research. Lancet 359:1599-1604. doi:10.1016/s01406736(02)08521-5

Ellsberg M, Jansen HA, Heise L, Watts CH, Garcia-Moreno C (2008) Intimate partner violence and women's physical and mental health in the WHO multi-country study on women's health and domestic violence: an observational study. Lancet 371:1165-1172. doi:10.1016/S0140-6736(08)60522-X

Garcia-Moreno C, Jansen HA, Ellsberg M, Heise L, Watts C (2006) Prevalence of intimate partner violence: findings from the WHO multi-country study on women's health and domestic violence. Lancet 368:1260-1269. doi:10.1016/S0140-6736(06)69523-8

Hines DA (2007) Predictors of sexual coercion against women and men: a multilevel, multinational study of university students. Arch Sex Behav 36:403-422. doi:10.1007/s10508-006-9141-4

Johnson MP (1995) Patriarchal terrorism and common couple violence: two forms of violence against women. J Marriage Fam 57:283-294. doi:10.2307/353683

Johnson MP, Ferraro KJ (2000) Research on domestic violence in the 1990s: making distinctions. J Marriage Fam 62:948-963. doi: $10.1111 / j .1741-3737.2000 .00948 . x$

Johnson H, Ollus N, Nevala S (2008) Violence against women. An international perspective. Springer, New York

Johnson MP, Leone JM, Xu Y (2014) Intimate terrorism and situational couple violence in general surveys: ex-spouses required. Violence Against Women 20:186-207. doi:10.1177/ 1077801214521324

Khalifeh H, Hargreaves J, Howard L, Birdthistle I (2013) Intimate partner violence and socioeconomic deprivation in England: findings from a national cross-sectional survey. Am J Public Health 103:462-472. doi:10.2105/AJPH.2012.300723 
Kimmel MS (2002) "Gender symmetry" in domestic violence: a substantive and methodological research review. Violence Against Women 8:1332-1363. doi:10.1177/107780102762478037

Krug EG, Dahlberg LL, Mercy JA, Zwi AB, Lozano R (2002) World report on violence and health. World Health Organization, Geneva

Lindert J, Luna J, Torres-Gonzalez F, Barros H, Ioannidi-Kapolou E, Quattrini S, Stankunas M, Soares JJ (2012) Study design, sampling and assessment methods of the European study 'abuse of the elderly in the European region'. Eur J Public Health 22:662-666. doi:10.1093/eurpub/ckr079

Lindert J, de Luna J, Torres-Gonzales F, Barros H, Ioannidi-Kopolou E, Melchiorre MG, Stankunas M, Macassa G, Soares JF (2013) Abuse and neglect of older persons in seven cities in seven countries in Europe: a cross-sectional community study. Int $\mathrm{J}$ Public Health 58:121-132. doi:10.1007/s00038-012-0388-3

Lovestad S, Krantz G (2012) Men's and women's exposure and perpetration of partner violence: an epidemiological study from Sweden. BMC Public Health 12:945. doi:10.1186/1471-245812-945

Nybergh L, Taft C, Enander V, Krantz G (2013) Self-reported exposure to intimate partner violence among women and men in Sweden: results from a population-based survey. BMC Public Health 13:845. doi:10.1186/1471-2458-13-845

Palermo T, Bleck J, Peterman A (2013) Tip of the Iceberg: reporting and gender-based violence in developing countries. Am J Epidemiol 179:602-612. doi:10.1093/aje/kwt295

Priebe S, Matanov A, Barros H, Canavan R, Gabor E, Greacen T, Holcnerová P, Kluge U, Nicaise P, Moskalewicz J, Díaz-Olalla JM, Strassmayr C, Schene AH, Soares JJ, Tulloch S, Gaddini A (2013) Mental health-care provision for marginalized groups across Europe: findings from the PROMO study. Eur J Public Health 23:97-103. doi:10.1093/eurpub/ckr214

Reid RJ, Bonomi AE, Rivara FP, Anderson ML, Fishman PA, Carrell DS, Thompson RS (2008) Intimate partner violence among men prevalence, chronicity, and health effects. Am J Prev Med 34:478-485. doi:10.1016/j.amepre.2008.01.029

Riggs DS, Caulfield MB, Street AE (2000) Risk for domestic violence: factors associated with perpetration and victimization. J Clin Psychol 56:1289-1316. doi:10.1002/1097-4679 (200010)56:10\%3C1289:AID-JCLP4\%3E3.0.CO;2-Z

Sorensen J, Kruse M, Gudex C, Helweg-Larsen K, Bronnum-Hansen $H$ (2012) Physical violence and health-related quality of life: danish cross-sectional analyses. Health Qual Life Outcomes 17:113. doi:10.1186/1477-7525-10-113

Stockl H, Heise L, Watts C (2011) Factors associated with violence by a current partner in a nationally representative sample of
German women. Sociol Health Illn 33:694-709. doi:10.1111/j. 1467-9566.2011.01319.x

Straus MA (2004) Cross-cultural reliability and validity of the revised conflict tactics scales: a study of university student dating couples in 17 nations. Cross-Cultural Res 38:407-432. doi:10.1177/1069397104269543

Straus MA (2012) Blaming the messenger for the bad news about partner violence by women: the methodological, theoretical, and value basis of the purported invalidity of the conflict tactics scales. Behav Sci Law 30:538-556. doi:10.1002/bs1.2023

Straus MA, Mickey EL (2012) Reliability, validity, and prevalence of partner violence measured by the conflict tactics scales in male-dominant nations. Aggress Violent Behav 17:463-474. doi:10.1016/j.avb.2012.06.004

Straus MA, Hamby S, Boney-McCoy S, Sugarman D (1996) The Revised Conflict Tactics Scales (CTS2). Development and preliminary psychometric data. J Fam Issues 17:283-316. doi: $10.1177 / 019251396017003001$

Straus MA, Hamby SL, Warren WL (2003) The conflict tactics scales handbook. Revised conflict tactics scales (CTS2). CTS: parentchild version (CTSPC). Western Psychological Services, Los Angeles

Thompson RS, Bonomi AE, Anderson M, Reid RJ, Dimer JA, Carrell D, Rivara FP (2006) Intimate partner violence: prevalence, types, and chronicity in adult women. Am J Prev Med 30:447-457. doi:10.1016/j.amepre.2006.01.016

Uthman OA, Lawoko S, Moradi T (2009) Factors associated with attitudes towards intimate partner violence against women: a comparative analysis of 17 sub-Saharan countries. BMC Int Health Hum Rights 9:14. doi:10.1186/1472-698x-9-14

Uthman OA, Lawoko S, Moradi T (2010) Sex disparities in attitudes towards intimate partner violence against women in sub-Saharan Africa: a socio-ecological analysis. BMC Public Health 10:223. doi:10.1186/1471-2458-10-223

Whitaker DJ, Haileyesus T, Swahn M, Saltzman LS (2007) Differences in frequency of violence and reported injury between relationships with reciprocal and nonreciprocal intimate partner violence. Am J Public Health 97:941-947. doi:10.2105/ajph. 2005.079020

WHO (2013) Global and regional estimates of violence against women: prevalence and health effects of intimate partner violence and nonpartner sexual violence. World Health Organization, Geneva

Yoshihama M, Horrocks J, Kamano S (2007) Experiences of intimate partner violence and related injuries among women in Yokohama, Japan. Am J Public Health 97:232-234. doi:10.2105/ AJPH.2005.078113 